\title{
National analysis of testicular and scrotal trauma in the USA
}

This article was published in the following Dove Press journal: Research and Reports in Urology

\section{Areg Grigorian Joshua K Livingston Sebastian D Schubl Bima J Hasjim \\ Daniel Mayers \\ Eric Kuncir \\ Cristobal Barrios \\ Victor Joe Jeffry Nahmias}

Division of Trauma, Burns and Surgical Critical Care, Department of Surgery, University of California, Irvine, Orange County, CA, USA
Correspondence: Areg Grigorian Division of Trauma, Burns and Surgical Critical Care, Department of Surgery, University of California, Irvine Medical Center, 333 The City Blvd West, Suite 1600, Irvine, Orange County, CA 928683298, USA

Tel + I 8184389093

Fax +I 7|4 4566070

Email agrigori@uci.edu
Background: To provide a descriptive analysis of scrotal and testicular trauma in the USA Additionally, we hypothesized that motorcycle collision would have a higher association with scrotal or testicular trauma and subsequent scrotal or testicular operation, compared to a bicycle collision.

Methods: The National Trauma Data Bank (2007-2015) was queried to identify adult male patients with scrotal or testicular trauma. A multivariable logistic regression analysis was performed.

Results: A total of 8,030 patients $(0.23 \%)$ had scrotal/testicular injury, with $44.6 \%$ involved in blunt trauma. A penetrating mechanism occurred in $50.5 \%$ of cases, with assault by firearm $(75.8 \%)$ being the most common. The median age of the patients was 31 years and the median injury severity score was 8 . Most had isolated scrotal or testicular trauma (74.5\%), with $48.3 \%$ requiring scrotal or testicular operation, most commonly repair of laceration (37.3\%). Patients involved in a motorcycle collision had higher risk for scrotal/testicular trauma $(\mathrm{OR}=5.40$, $\mathrm{CI}=4.40-6.61, p=0.0004)$ and subsequent scrotal/testicular surgery $(\mathrm{OR}=4.93, \mathrm{CI}=3.82-6.36$, $p=0.0005$ ), compared to bicycle collision.

Conclusion: Scrotal or testicular trauma is rare but occurs most commonly after assault by firearm. Most patients only have isolated scrotal or testicular trauma, but nearly half require subsequent scrotal or testicular operation. Trauma patients presenting after a motorcycle collision have a higher association of scrotal or testicular trauma and subsequent surgery when compared to those involved in a bicycle collision.

Keywords: scrotal trauma, testicular trauma, testes, scrotal surgery, testicular surgery

\section{Introduction}

The scrotum is relatively protected from severe damage due to its inherent mobility and the presence of the cremasteric reflex and tunica albuginea. ${ }^{1}$ The incidence of scrotal or testicular injury in trauma is $<1 \%$, and while it is generally not life threatening, prompt diagnosis and appropriate management are critical to prevent morbidity. ${ }^{2-4}$ The American Urological Association recommends early scrotal exploration in all patients suspected of testicular rupture to prevent testicular loss, infection, chronic pain, infertility, and altered self-image. ${ }^{5}$ Common blunt mechanisms of injury in scrotal trauma include motor vehicle, motorcycle, and bicycle accidents. ${ }^{6}$

To that end, a recent descriptive analysis from a French database regarding genitourinary injury (GUI) found motorcyclists, followed by bicyclists to have the highest incidence of scrotal or testicular injury. ${ }^{7}$ This is presumably because motorcyclists are vulnerable to high-impact collisions, whereas bicyclists incur less significant force 
velocity. Interestingly, according to the Pew Research Center, $59 \%$ of the French population owns a bicycle compared to $53 \%$ in the USA, but more Americans own a motorcycle than in France ( $14 \%$ vs $12 \%) .{ }^{8}$ This suggests that the incidence of scrotal or testicular trauma in the USA may be different than in France. Accordingly, we first sought to provide a descriptive analysis of scrotal and testicular trauma in the USA. Additionally, we hypothesized that in the USA, motorcycle collision would have a higher association with scrotal or testicular trauma and subsequent scrotal or testicular operation, compared to a bicycle collision.

\section{Methods}

This work was approved by the institutional review board of the University of California, Irvine. The National Trauma Data Bank (NTDB) is a multicenter registry of trauma centers in North America maintained by the American College of Surgeons Committee on Trauma. Each year, there is an updated cohort of patients added to the database. All patients admitted from January 2007 through December 2015 who were $>18$ years of age were included. The primary end points of interest included the incidence of scrotal or testicular injury and subsequent scrotal or testicular operation, defined by the International Classification of Diseases version-9: scrotal/ testicular trauma, 878.2/878.3; scrotal/testicular operation, 61-63.99. The NTDB does not differentiate between scrotal and testicular trauma as these injuries are grouped together. Isolated scrotal or testicular trauma was indicated in patients that did not have any other GUIs. A descriptive analysis of all trauma patients with scrotal or testicular trauma was performed. Next, patients with scrotal or testicular trauma after a bicycle collision were compared to those presenting after a motorcycle collision. Secondary outcomes evaluated included total hospital length of stay (LOS), intensive care unit (ICU) LOS, ventilator days, acute kidney injury, acute respiratory distress syndrome, myocardial infarction, pulmonary embolism, deep vein thrombosis, pneumonia, urinary tract infection, severe sepsis, unplanned intubation or ICU admission, penile operation, and mortality.

Patient demographic information including age, gender, and prehospital comorbidities were collected. Prehospital comorbidities included congestive heart failure, hypertension, peripheral vascular disease, myocardial infarction, smoking, end-stage renal disease, chronic obstructive pulmonary disease, and cerebrovascular accident. The injury profile included the injury severity score (ISS) and mechanism of injury. Any associated kidney, bladder, urethra, ureter, adrenal gland, penile, pelvis, spine, and traumatic brain injury was also included. All variables were coded as present or absent.

A Student's $t$-test was used to compare continuous variables, and $\chi^{2}$ was used to compare categorical variables for bivariate analysis. Categorical data were reported as percentages, and continuous data were reported as medians with interquartile range.

The magnitude of the association between predictor variables and the incidence of scrotal or testicular trauma and subsequent scrotal or testicular operation were individually measured using a univariable logistic regression model. Covariates including age $>65$ and ISS $>16$ were controlled for using a hierarchical multivariable logistic regression model and risk for outcomes were reported with an OR and 95\% CI. All $p$-values were 2-sided, with a statistical significance level of $<0.05$. All analyses were performed with IBM SPSS Statistics for Windows (Version 24, IBM Corporation, Armonk, NY, USA).

This research involved humans. However, since this retrospective study was performed using a national database with deidentified patients, risk to participants is minimal. Additionally, the NTDB does not hold any identifying patient data. There is no consent required.

\section{Results}

\section{Demographics of all adult patients with scrotal and testicular trauma}

From 3,489,850 male trauma patients, 8,030 were identified to have a scrotal or testicular injury $(0.2 \%)$ with less than half $(44.6 \%)$ involved in blunt trauma. Of these, the most common mechanisms, in order, were motorcycle collision (38.5\%), motor vehicle accident $(21.3 \%)$, pedestrian collision (15.8\%), and bicycle collision $(2.8 \%)$. A penetrating mechanism occurred in $50.5 \%$ of cases, with assault by firearm $(75.8 \%)$ being the most common. The median age of all patients with scrotal or testicular injury was 31 years, and the median ISS was 8 . The most common comorbidity was smoking (16.6\%). Most patients had isolated scrotal or testicular trauma (74.5\%), and the most commonly associated GUI was penile (16.2\%) (Table 1).

\section{Outcomes of all adult patients with scrotal and testicular trauma}

The median hospital LOS was 3 days, and the median ICU LOS was 4 days. Nearly half of the patients (48.3\%) with scrotal or testicular trauma underwent a subsequent scrotal or testicular operation. The most common operation was repair 
Table I Characteristics of adult trauma patients with scrotal or testicular injury

\begin{tabular}{|c|c|}
\hline Characteristics & $\begin{array}{l}\text { Scrotal/testicular } \\
\text { trauma }(n=8,030)\end{array}$ \\
\hline Age, years, median (IQR) & $31.0(7)$ \\
\hline \multicolumn{2}{|l|}{ Comorbidities, n (\%) } \\
\hline Smoking & I,332 (16.6) \\
\hline Hypertension & $721(9.0)$ \\
\hline COPD & $267(3.3)$ \\
\hline Congestive heart failure & $24(0.3)$ \\
\hline Myocardial infarction & $23(0.3)$ \\
\hline Cerebrovascular accident & $21(0.3)$ \\
\hline Peripheral vascular disease & $9(0.1)$ \\
\hline End-stage renal disease & $8(0.1)$ \\
\hline ISS, median (IQR) & $8.0(18)$ \\
\hline Penetrating mechanism, n (\%) & $4,054(50.5)$ \\
\hline Assault by firearm & $3,073(75.8)$ \\
\hline Suicide/self-inflicted injury & $154(5.8)$ \\
\hline Blunt mechanism, n (\%) & $3,579(44.6)$ \\
\hline Motorcycle & I,377 (38.5) \\
\hline Motor vehicle accident & $763(21.3)$ \\
\hline Pedestrian & $567(\mid 5.8)$ \\
\hline Bicycle & $100(2.8)$ \\
\hline \multicolumn{2}{|l|}{ Genitourinary injuries, n (\%) } \\
\hline Isolated scrotal ${ }^{\mathrm{a}}$ & $5,986(74.5)$ \\
\hline Penile & $1,300(16.2)$ \\
\hline Bladder or urethra & $750(9.3)$ \\
\hline Kidney & $222(2.8)$ \\
\hline Ureter & $53(0.7)$ \\
\hline Adrenal gland & $53(0.7)$ \\
\hline \multicolumn{2}{|l|}{ Additional injuries, n (\%) } \\
\hline Pelvic fracture & $1,812(22.6)$ \\
\hline Spinal injury & I,203 (I5.0) \\
\hline Traumatic brain injury & $\mathrm{I}, 127(14.0)$ \\
\hline
\end{tabular}

Note: a Considered isolated if no other genitourinary injury present. Abbreviations: COPD, chronic obstructive pulmonary disease; IQR, interquartile range; ISS, injury severity score.

of laceration of scrotum or testis (37.3\%), followed by unilateral orchiectomy (23.4\%). The most common in-hospital complication was pneumonia (3.1\%) (Table 2).

\section{Characteristics of scrotal and testicular trauma patients involved in motorcycle or bicycle collision}

Compared to patients involved in a motorcycle collision, those involved in a bicycle collision had a lower median ISS ( 5 vs $17, p=0.0002$ ) but higher incidence of associated penile trauma $(17.0 \%$ vs $6.9 \%, p=0.0005)$. There was no difference in all other GUI (Table 3). Compared to patients involved in a bicycle collision, those involved in a motorcycle collision had a shorter ICU LOS ( 5 vs 8 days, $p=0.02$ ) and ventilator days ( 5 vs $7, p=0.01)$ with a lower proportion requiring penile surgery $(2.5 \%$ vs $9.0 \%, p=0.0002)$. There were no differences in all other in-hospital complications examined $(p>0.05)$.
Table 2 Outcomes, complications, and interventions in adult trauma patients with scrotal or testicular injury

\begin{tabular}{ll}
\hline Outcomes & $\begin{array}{l}\text { Scrotal/testicular } \\
\text { trauma }(\mathbf{n}=8,030)\end{array}$ \\
\hline Surgery, $\mathrm{n}(\%)$ & $3,882(48.3)$ \\
Scrotal/testicular operation & $716(8.9)$ \\
Penile operation & $3.0(4)$ \\
LOS, days, median (IQR) & $4.0(3)$ \\
ICU, days, median (IQR) & $3.0(2)$ \\
Ventilator, days, median (IQR) & \\
Complications, $\mathrm{n}(\%)$ & $249(3.1)$ \\
Pneumonia & $188(2.3)$ \\
Deep vein thrombosis & $130(1.6)$ \\
ARDS & $129(1.6)$ \\
Acute kidney injury & $69(0.9)$ \\
Urinary tract infection & $57(0.7)$ \\
Unplanned intubation & $46(0.6)$ \\
Pulmonary embolism & $44(0.5)$ \\
Severe sepsis & $34(0.4)$ \\
Unplanned ICU admission & $8(0.1)$ \\
Myocardial infarction & $609(7.6)$ \\
\hline Mortality, n (\%) & .
\end{tabular}

Abbreviations: ARDS, acute respiratory distress syndrome; ICU, intensive care unit; IQR, interquartile range; LOS, length of stay.

\section{Multivariable regression analysis for risk of scrotal or testicular injury in trauma patients and secondary outcomes}

The covariates in the multivariable analysis included age $>65$ and ISS $>16$. In comparison to all patients involved in a bicycle collision, those involved in a motorcycle collision had a 5 -fold relative increase in incidence of scrotal or testicular trauma $(\mathrm{OR}=5.40,95 \% \mathrm{CI}=4.40-6.61, p=0.0004)$ and need for subsequent scrotal/testicular surgery $(\mathrm{OR}=4.93,95 \%$ CI=3.82-6.36, $p=0.0005$ ) (Table 4).

\section{Discussion}

We performed a descriptive analysis of scrotal and testicular trauma in the USA, using 9 years of data from a large national database, and found the incidence to be $0.2 \%$ and occurring primarily in younger adults. Penetrating trauma was the most common overall mechanism, with assault by firearm being the most common penetrating injury. Of blunt traumas, the most common was a motorcycle accident. The majority of patients had isolated scrotal or testicular trauma. Most patients had a relatively short hospital stay (3 days). However, nearly half required a scrotal/testicular operation, with repair of laceration being the most common procedure performed. Trauma patients presenting after a motorcycle collision had a higher association with scrotal or testicular trauma and subsequent surgery when compared to those involved in a bicycle collision. 
Table 3 Characteristics of trauma patients with scrotal or testicular injury after motorcycle or bicycle collision

\begin{tabular}{|c|c|c|c|}
\hline Characteristics & $\begin{array}{l}\text { Motorcyclists } \\
(n=1,377)\end{array}$ & $\begin{array}{l}\text { Bicyclists } \\
(n=100)\end{array}$ & $p$-value \\
\hline Age, years, median (IQR) & $35.0(23)$ & $37.0(23)$ & 0.28 \\
\hline \multicolumn{4}{|l|}{ Comorbidities, n (\%) } \\
\hline Smoking & $210(15.3)$ & $17(17.0)$ & 0.64 \\
\hline Hypertension & $120(8.7)$ & $7(7.0)$ & 0.56 \\
\hline COPD & $24(1.7)$ & $3(3.0)$ & 0.35 \\
\hline Myocardial infarction & $5(0.4)$ & $2(2.0)$ & 0.01 \\
\hline Congestive heart failure & $7(0.5)$ & $\mathrm{I}(\mathrm{I} .0)$ & 0.52 \\
\hline Cerebrovascular accident & $3(0.2)$ & 0 & 0.64 \\
\hline PVD & $3(0.2)$ & 0 & 0.64 \\
\hline End-stage renal disease & $2(0.1)$ & 0 & 0.73 \\
\hline ISS, median (IQR) & $17.0(18)$ & $5.0(13)$ & 0.0002 \\
\hline \multicolumn{4}{|l|}{ Genitourinary injuries, n (\%) } \\
\hline |solated scrotal ${ }^{\mathrm{a}}$ & $\mathrm{I}, 100(79.9)$ & $78(78.0)$ & 0.65 \\
\hline Bladder or urethra & $146(10.6)$ & $5(5.0)$ & 0.07 \\
\hline Penile & $95(6.9)$ & $17(17.0)$ & 0.0005 \\
\hline Kidney & $50(3.6)$ & $2(2.0)$ & 0.39 \\
\hline Ureter & $8(0.6)$ & I (I.0) & 0.60 \\
\hline Adrenal gland & $19(1.4)$ & 0 & 0.24 \\
\hline \multicolumn{4}{|l|}{ Additional injuries, $\mathrm{n}(\%)$} \\
\hline Pelvic fracture & $688(50.0)$ & $28(28.0)$ & 0.0004 \\
\hline Traumatic brain injury & $479(34.8)$ & $16(16.0)$ & 0.0008 \\
\hline Spinal injury & $450(32.7)$ & $24(24.0)$ & 0.07 \\
\hline
\end{tabular}

Note: aConsidered isolated if no other genitourinary injury present.

Abbreviations: COPD, chronic obstructive pulmonary disease; IQR, interquartile range; ISS, injury severity score; PVD, peripheral vascular disease.

Table 4 Multivariable logistic regression analysis ${ }^{a}$ of outcomes in trauma patients involved in a motorcycle collision versus bicycle collision

\begin{tabular}{llll}
\hline Outcome & OR & Cl & p-value \\
\hline Scrotal/testicular trauma & 5.40 & $4.40-6.61$ & 0.0004 \\
Scrotal surgery after scrotal/testicular & 4.93 & $3.82-6.36$ & 0.0005 \\
trauma & & &
\end{tabular}

Note: ${ }^{\text {aAll }}$ models controlled for age $\geq 65$ and ISS $\geq 16$.

Abbreviation: ISS, injury severity score.

The incidence of scrotal or testicular trauma is rare. Similar to a previous report, we found the incidence to be $<1 \%{ }^{4}$ Previous studies have found that blunt mechanism is the most common mechanism leading to genitourinary trauma, occurring in up to $85 \%$ of cases of scrotal or testicular injury, whereas our study found that only $44.6 \%$ of cases presented after a blunt mechanism, whereas $50.5 \%$ were involved in a penetrating mechanism (with the majority being due to assault with a firearm). ${ }^{4,9,10}$ This may be due to our study providing an analysis based on a national database, with a wide range of participating trauma centers, including large urban trauma centers with a high volume of penetrating trauma.

In cases of blunt trauma, scrotal or testicular injury commonly occurs in motorcyclists and bicyclists. Using a large
French database, Terrier et $\mathrm{al}^{7}$ showed that $72 \%$ of cases of blunt scrotal or testicular trauma occurred after a motorcycle collision, whereas $20 \%$ were due to a bicycle collision. The remainder were either from a motor vehicle collision or involving a pedestrian struck by a vehicle. In our study, $38.5 \%$ of blunt scrotal or testicular trauma cases involved a motorcycle, $21.3 \%$ a motor vehicle, and $2.8 \%$ a bicycle. One explanation for the higher rate of bicycle collisions leading to a scrotal or testicular injury in the French study is the fact that more French citizens ride bicycles compared to people within the USA. ${ }^{8}$ Interestingly, although more Americans ride motorcycles compared to the French population, the rate of motorcycle collisions leading to scrotal or testicular trauma in the USA was much lower compared to the French population (17.1\% vs $72.0 \%)$. Traffic conditions, laws, and norms may help explain the difference. According to the International Road Traffic and Accident Database, young French adults have among the highest mortality and morbidity rates in European countries. ${ }^{11}$ The incidence of major traumatic injuries, such as spinal cord injury, in French motorcyclists has increased based on an epidemiological study. ${ }^{12}$ In contrast, the injury rate in motorcyclists from the USA has decreased $6.2 \%$ from 2007 to $2015 .{ }^{13}$ Laws governing protective gear may be responsible for this trend. For example, after implementing a universal motorcycle helmet law in California, the fatality rate dramatically decreased by nearly $40 \% .{ }^{14}$ More states have implemented laws mandating the use of helmets in motorcyclists. ${ }^{15,16}$ This conscious effort and public safety awareness of the benefits of helmet use in motorcyclists may translate to additional protective gear, such as armored clothing with high-density foam panels that may protect the groin and help prevent scrotal and testicular trauma. Additional epidemiologic studies investigating traffic conditions, laws, and norms between French and USA motorcyclists can help further explain this difference.

Protective gear and proper saddle positioning may play a role in preventing GUI after bicycle collisions. In our study, we found more bicyclists with scrotal or testicular trauma had a concomitant penile injury, compared to motorcyclists. This is a particularly interesting finding when considering that a motorcycle collision has more than a 5-fold higher risk of scrotal or testicular injury compared to a bicycle collision. Men's bicycles have a top tube that runs from the seat to the handlebar. In comparison, women's bicycles have a lower set bar which allows them to mount the bicycle with a dress - a feature that is outdated in the modern era. ${ }^{17}$ The higher location of the top tube on men's bicycles has been associated with penile trauma after bicycle collisions in which the 
rider accelerates forward. ${ }^{18,19}$ Bicycle manufacturers should be aware of this problem to design the frame and seating in a way to circumvent this potential injury. Additionally, protective gear may help decrease the rate of penile trauma in both bicycle and motorcycle collisions. In a single-center retrospective study of all patients admitted with GUI after bicycle collisions, Yelon et $\mathrm{a}^{20}$ found that all of the patients with these injuries were not wearing protective gear or padded shorts. Furthermore, the saddle in which the rider sits may also play a role in GUI after bicycle collisions. To avoid stresses within the perineum and provide efficient support, the saddle needs to be at least 2 times wider than the bi-ischial width of the cyclist. ${ }^{21}$ Compared to the female pelvis, males have a steeper arch of the pubic symphysis, which exposes the rider to the metal handlebar or head tube during collision as opposed to the cushioned anterior nose of the saddle. ${ }^{22}$ Future research on ideal bicycle design, seating, and protective gear/ clothing is warranted to help prevent GUI.

Our study has several limitations. Reporter bias is inherent in all large national databases that depend on voluntary participation, and all our data were restricted to information provided in the NTDB, which is also subject to input error. Not all data fields were complete, and some variables had missing or incomplete information. Notable data fields relevant to our study that are missing include speed of the collision and if the motorcycle or bicycle rider was wearing protective gear. Additionally, the NTDB does not include information on American Association for the Surgery of Trauma grading system or other urologic grading systems for scrotal and testicular injuries. ${ }^{23}$ Without this information, it is not possible to discern a small scrotal contusion from a large avulsion or a testicular contusion from testicular rupture.

\section{Conclusion}

Scrotal or testicular trauma is rare but occurs most commonly after assault by firearm. Most patients only have isolated scrotal or testicular trauma requiring a short hospital stay, but nearly half do require a scrotal or testicular operation, most commonly to repair laceration of the scrotum or testis. Trauma patients presenting after a motorcycle collision have a higher association with scrotal or testicular trauma and subsequent surgery when compared to those involved in a bicycle collision. Future prospective research should investigate the role that protective gear may have in reducing scrotal or testicular trauma and/or subsequent need for scrotal or testicular surgery, especially in motorcycle and bicycle collisions.

\section{Acknowledgment}

The abstract for this manuscript was presented at the 70th Annual Meeting for Southwestern Surgical Congress, April 8-11, 2018 at Napa, CA, USA.

\section{Disclosure}

The authors report no other conflicts of interest in this work.

\section{References}

1. Bocchi F, Benecchi L, Russo F, et al. Early exploratory intervention in scrotal trauma. Urologia. 2013;80(2):140-144.

2. Gross M. Rupture of the testicle: the importance of early surgical treatment. J Urol. 1969;101(2):196-197.

3. Simhan J, Rothman J, Canter D, et al. Gunshot wounds to the scrotum: a large single-institutional 20-year experience. BJU Int. 2012;109(11):1704-1707.

4. Cass AS, Luxenberg M. Testicular injuries. Urology. 1991;37(6):528-530.

5. Morey AF, Brandes S, Dugi DD 3rd, et al. Urotrauma: AUA guideline. J Urol. 2014;192(2):327-335.

6. Paparel P, N'Diaye A, Laumon B, Caillot JL, Perrin P, Ruffion A. The epidemiology of trauma of the genitourinary system after traffic accidents: analysis of a register of over 43,000 victims. BJU Int. 2006;97(2):338-341.

7. Terrier JE, Paparel P, Gadegbeku B, Ruffion A, Jenkins LC, N'Diaye A. Genitourinary injuries after traffic accidents: analysis of a registry of 162,690 victims. J Trauma Acute Care Surg. 2017;82(6):1087-1093.

8. Pew Research Center. 2015. Available from: https://www.pewresearch. org/fact-tank/2015/04/16/car-bike-or-motorcycle-depends-on-whereyou-live/. Accessed December 13, 2017.

9. McAninch JW, Kahn RI, Jeffrey RB, Laing FC, Krieger MJ. Major traumatic and septic genital injuries. J Trauma. 1984;24(4):291-298.

10. Morey AF, Metro MJ, Carney KJ, Miller KS, McAninch JW. Consensus on genitourinary trauma: external genitalia. BJU Int. 2004;94(4):507-515.

11. IRTAD (International Road Traffic and Accident Database). Key Transport Statistics 2016. 2016. Available from: https://www.itf-oecd. org/IRTAD. Accessed July 03, 2018.

12. Lieutaud T, Ndiaye A, Laumon B, Chiron M. Spinal cord injuries sustained in road crashes are not on the decrease in france: a study based on epidemiological trends. J Neurotrauma. 2012;29(3): 479-487.

13. National Center for Statistics and Analysis (NCSA). Motor Vehicle Traffic Crash Data Resource. 2016. Available from: https://crashstatsnhtsadotgov/Api/Public/ViewPublication/812492html. Accessed July 03, 2018.

14. Kraus JF, Peek C, McArthur DL, Williams A. The effect of the 1992 California motorcycle helmet use law on motorcycle crash fatalities and injuries. JAMA. 1994;272(19):1506-1511.

15. Olsen CS, Thomas AM, Singleton M, et al. Motorcycle helmet effectiveness in reducing head, face and brain injuries by state and helmet law. Inj Epidemiol. 2016;3(1):8.

16. Eltorai AE, Simon C, Choi A, Hsia K, Born CT, Daniels AH. Federally mandating motorcycle helmets in the United States. BMC Public Health. 2016;16(1):242.

17. Marceau L, Kleinman K, Goldstein I, McKinlay J. Does bicycling contribute to the risk of erectile dysfunction? Results from the Massachusetts Male Aging Study (MMAS). Int J Impot Res. 2001;13(5):298-302.

18. Schwarzer U, Sommer F, Klotz T, Cremer C, Engelmann U. Cycling and penile oxygen pressure: the type of saddle matters. Eur Urol. 2002;41(2):139-143.

19. Sommer F, Konig D, Graft C, et al. Impotence and genital numbness in cyclists. Int J Sports Med. 2001;22(6):410-413. 
20. Yelon JA, Harrigan N, Evans JT. Bicycle trauma: a five-year experience. Am Surg. 1995;61(3):202-205.

21. Spears IR, Cummins NK, Brenchley Z, et al. The effect of saddle design on stresses in the perineum during cycling. Med Sci Sports Exerc. 2003;35(9):1620-1625.
22. Cohen GC. Cycling injuries. Can Fam Physician. 1993;39: 628-632.

23. Moore EE, Malangoni MA, Cogbill TH, et al. Organ injury scaling VII: cervical vascular, peripheral vascular, adrenal, penis, testis, and scrotum. J Trauma. 1996;41(3):523-524.

\section{Publish your work in this journal}

Research and Reports in Urology is an international, peer-reviewed, open access journal publishing original research, reports, editorials, reviews and commentaries on all aspects of adult and pediatric urology in the clinic and laboratory including the following topics: Pathology, pathophysiology of urological disease; Investigation and treatment of urological disease; Pharmacology of drugs used for the treatment of urological disease. The manuscript management system is completely online and includes a very quick and fair peer-review system, which is all easy to use. Visit http://www.dovepress.com/testimonials.php to read real quotes from published authors.

Submit your manuscript here: https://www.dovepress.com/research-and-reports-in-urology-journal 